\title{
Intracerebral hemorrhage in a patient with tuberous sclerosis complex
}

Lei Yang, Wei Qin, Wenli Hu

Department of Neurology, Beijing Chaoyang Hospital, Capital Medical University, Beijing, China

Submitted: 31 December 2015

Accepted: 27 April 2016

Arch Med Sci 2018; 14, 4: 945-949

DOI: https://doi.org/10.5114/aoms.2016.60604

Copyright $\odot 2016$ Termedia \& Banach

Tuberous sclerosis complex (TSC) is an autosomal dominant disorder that results from mutations in the TSC1 or TSC2 gene. The disease is characterized by hamartomatous lesions in multiple organ systems. It is the second most common neurocutaneous syndrome after neurofibromatosis [1] with an estimated prevalence ranging from 1/6000 to $1 / 12000$ [2]. About two-thirds of cases are sporadic [3]. In China, there are no definite results of morbidity and mortality for TSC. Central nervous system manifestations are common sources of morbidity, including infantile spasms, seizures, intellectual disability, and giant-cell astrocytomas. There are rare case reports of cerebral hemorrhage and aneurysm in patients with TSC. But there has been no report of basal ganglia hemorrhage in patients with TSC.

A 38-year-old, right-handed man was admitted to the hospital because of right limb weakness and headache.

The patient had been well until $3 \mathrm{~h}$ earlier, when he had headache and weakness of the right side of the body and slurred speech when he awoke from sleep after dinner. There was no vertigo, dizziness, hemisensory change or palpitations. In the emergency department of our hospital, he received a cranial computed tomography (CT) scan which showed acute left basal ganglia hemorrhage with multiple subependymal calcifications. His stroke risk factor was 10 pack-years of smoking. This patient was mildly mentally retarded and had had no seizure. His blood pressure had been found to be higher than normal for six months, but he had not been taking any antihypertensive drugs.

Abdominal magnetic resonance imaging (MRI) performed 6 months previously in our outpatient department for a painless left abdominal mass showed bilaterally enlarged kidneys with diffuse renal disease suggestive of angiomyolipomas. Abnormal signs were also seen in the liver. He had no history of seizure or abnormal movements suspected to be convulsions. There was no family history of kidney diseases, tumor or stroke.

On general physical examination, his temperature was $36^{\circ} \mathrm{C}$, and the blood pressure was $160 / 100 \mathrm{~mm} \mathrm{Hg}$. Skin examination revealed multiple angiofibromas on the face and neck (Figures 1,2), and ungual fibromas and multiple hypopigmented lesions over the chest, abdomen, and extremities. No bruits were heard around the neck. Examination of the heart revealed no abnormalities. Neurologic examination revealed dysarthria, right lower facial weakness, tongue deviation to the right, and right upper and lower extremity weakness with 0/5 power. Reflexes of

\author{
Corresponding author: \\ Wenli Hu \\ Department of Neurology \\ Beijing Chaoyang Hospital \\ Capital Medical University \\ 8 Bai Jia Zhuang Road \\ Chaoyang District \\ Beijing 100020, China \\ Phone: 86-010-85231548 \\ E-mail: huwenli@sina.com
}




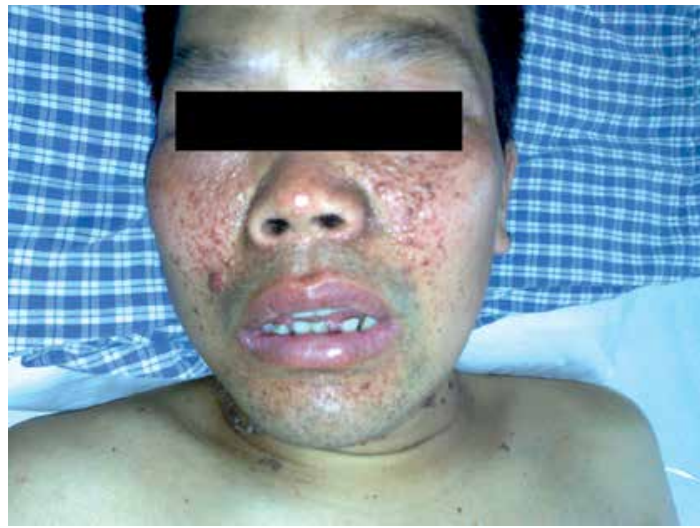

Figure 1. Multiple angiofibromas on face

his right side were negative. Creatine kinase was found to be high $(150.6 \mu \mathrm{mol} / \mathrm{l})$ upon admission to the emergency department. The clinical data are summarized in Table I.

After hospitalization, his blood creatinine level was $121.2 \mu \mathrm{mol} / \mathrm{l}$. Erythrocyte sedimentation rate was $51 \mathrm{~mm} / \mathrm{h}$. The thyroid function test showed normal levels of free thyroxin and thyroid-stimulating hormone, and low levels of serum free triiodothyronine. Complete blood count was normal. The levels of aspartate aminotransferase $(24 \mathrm{U} / \mathrm{l})$, alanine aminotransferase, urea nitrogen, glucose, total bilirubin, albumin, globulin and creatine kinase were normal. High-density lipoprotein cholesterol, low-density lipoprotein cholesterol and triglycerides were normal, with the results being $1.26 \mathrm{mmol} / \mathrm{l}, 3.24 \mathrm{mmol} / \mathrm{l}$ and $2.0 \mathrm{mmol} / \mathrm{l}$ respectively. Prothrombin time and partial thromboplastin time were normal. The plasma homocysteine level was normal. Syphilis and HIV serology were negative. Cardiac evaluation including elec-

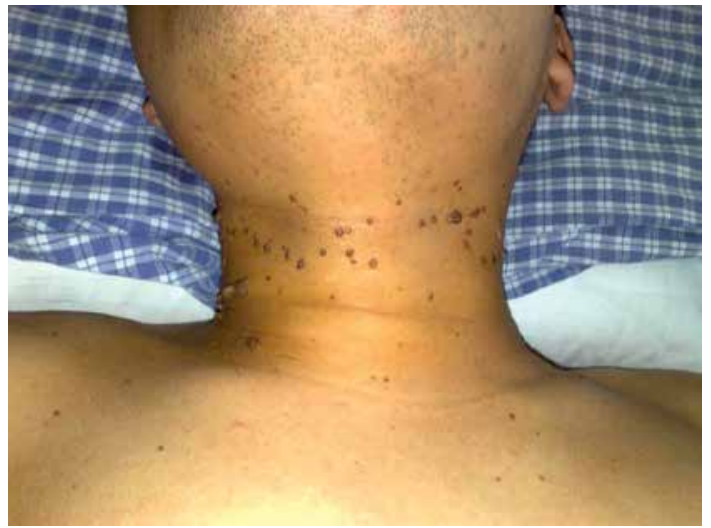

Figure 2. Multiple angiofibromas on neck

trocardiogram and heart ultrasound was normal. Major results of blood and plasma markers are shown in Table II.

Cranial CT revealed acute left basal ganglia hemorrhage with multiple subependymal calcifications (Figure 3). Abdominal MRI performed 6 months previously showed bilaterally enlarged kidneys with heterogeneous enhancement suggestive of angiomyolipomas (Figures 4, 5). Abnormal signs were also seen in the liver - hepatic angiomyolipoma (Figures 6, 7). Magnetic resonance angiography (MRA) was normal (Figure 8).

The patient received mannitol 20\% $125 \mathrm{ml}$ IV every $8 \mathrm{~h}$ for 3 days, which was tapered in the next 3 days to $125 \mathrm{ml}$ every $12 \mathrm{~h}$. The antihypertensive medication amlodipine was started and famotidine was used to prevent stress ulcer. Measures such as frequent position changes and chest percussion were performed to prevent hypostatic pneumonia and pressure sores; early mobilization was carried out to prevent limb contracture and

Table I. Summary of the patient's clinical features with reference to the diagnostic criteria of the 2012 edition [4]

\begin{tabular}{|c|c|c|c|}
\hline Major features & & Minor featu & \\
\hline $\begin{array}{l}\text { Hypomelanotic macules } \\
(\geq 3 \text {, at least } 5 \mathrm{~mm} \text { diameter })\end{array}$ & + & "Confetti" skin lesions & - \\
\hline $\begin{array}{l}\text { Angiofibromas }(\geq 3) \text { or fibrous cephalic } \\
\text { plaque }\end{array}$ & + & Dental enamel pits (> 3) & - \\
\hline Ungual fibromas $(\geq 2)$ & + & Intraoral fibromas $(\geq 2)$ & - \\
\hline Shagreen patch & - & Retinal achromic patch & / \\
\hline Multiple retinal hamartomas & / & Multiple renal cysts & - \\
\hline Cortical dysplasias & - & Nonrenal hamartomas & + \\
\hline Subependymal nodules & + & & \\
\hline Subependymal giant cell astrocytoma & / & & \\
\hline Cardiac rhabdomyoma & - & & \\
\hline Lymphangioleiomyomatosis (LAM) & - & & \\
\hline Angiomyolipomas ( $\geq 2$ ) & + & & \\
\hline
\end{tabular}


Table II. Major results of the blood and plasma workup

\begin{tabular}{|lclc|}
\hline Erythrocyte sedimentation rate & $51 \mathrm{~mm} / \mathrm{h}$ & High-density lipoprotein cholesterol & $1.26 \mathrm{mmol} / \mathrm{l}$ \\
\hline Blood creatinine & $121.2 \mu \mathrm{mol} / \mathrm{l}$ & Low-density lipoprotein cholesterol & $3.24 \mathrm{mmol} / \mathrm{l}$ \\
\hline Free thyroxin & $1.21 \mathrm{ng} / \mathrm{dl}$ & Triglycerides & $2.0 \mathrm{mmol} / \mathrm{l}$ \\
\hline Thyroid-stimulating hormone & $2.525 \mu \mathrm{IU} / \mathrm{ml}$ & Prothrombin time & $11.2 \mathrm{~s}$ \\
\hline Free triiodothyronine & $1.29 \mathrm{ng} / \mathrm{dl}$ & Partial thromboplastin time & $29.6 \mathrm{~s}$ \\
\hline Aspartate aminotransferase & $24 \mathrm{U} / \mathrm{l}$ & Homocysteine & $12 \mu \mathrm{mol} / \mathrm{l}$ \\
\hline Alanine aminotransferase & $12 \mathrm{U} / \mathrm{l}$ & Urea nitrogen & $246.02 \mu \mathrm{mol} / \mathrm{l}$ \\
\hline
\end{tabular}

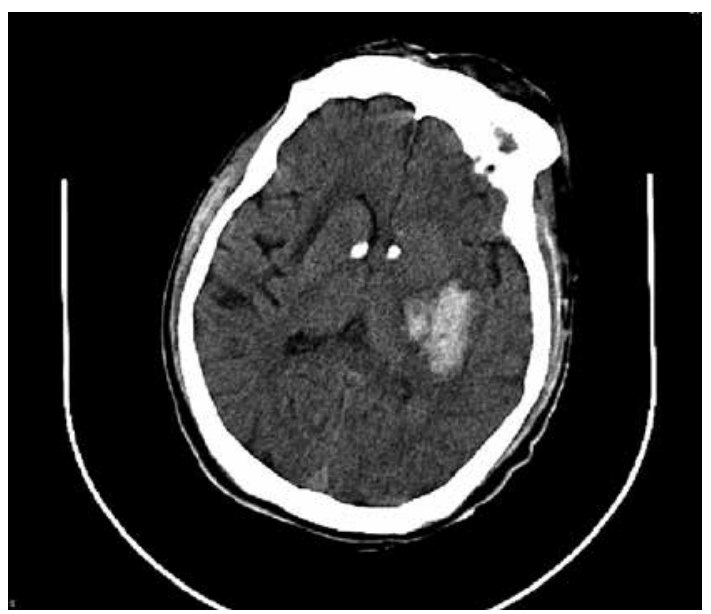

Figure 3. Acute left basal ganglia hemorrhage. Also there were multiple subependymal calcifications

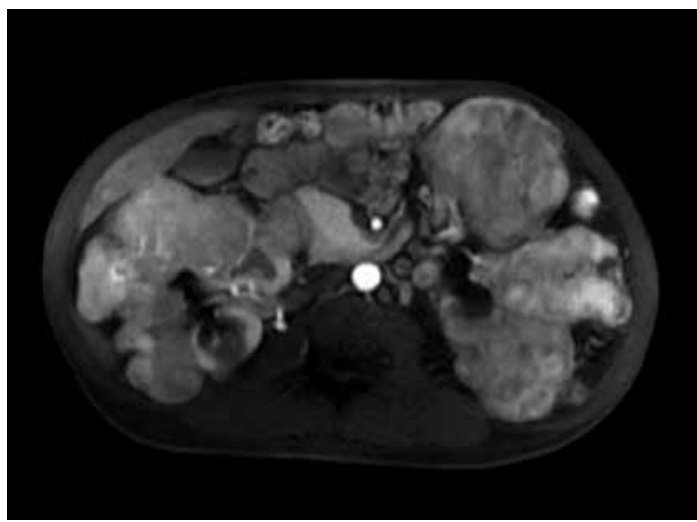

Figure 5. Bilaterally enlarged kidneys with heterogeneous enhancement

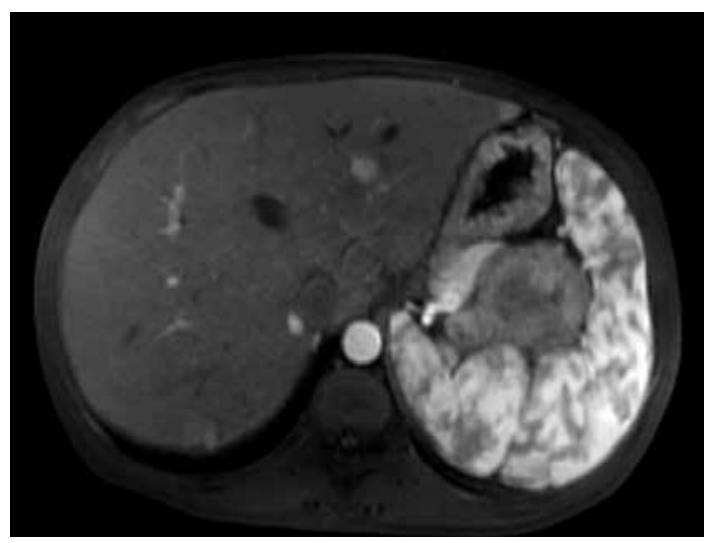

Figure 7. Multiple nodules in liver, significantly enhanced

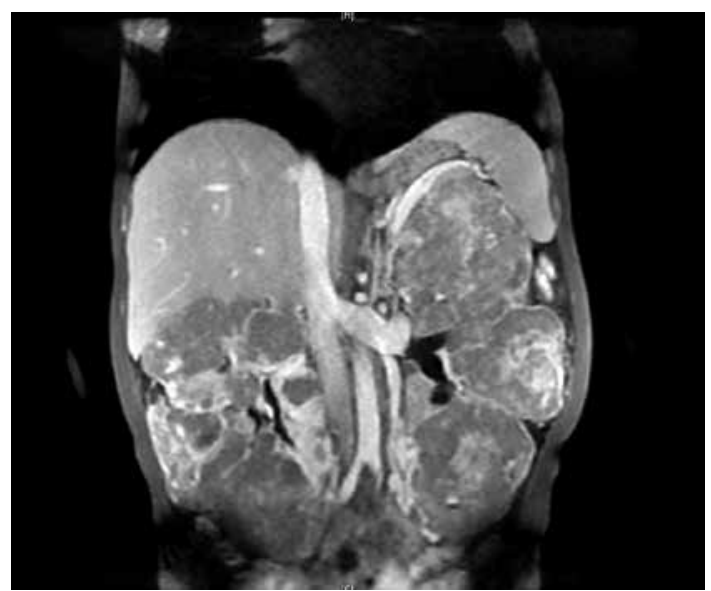

Figure 4. Bilaterally enlarged kidneys with heterogeneous enhancement

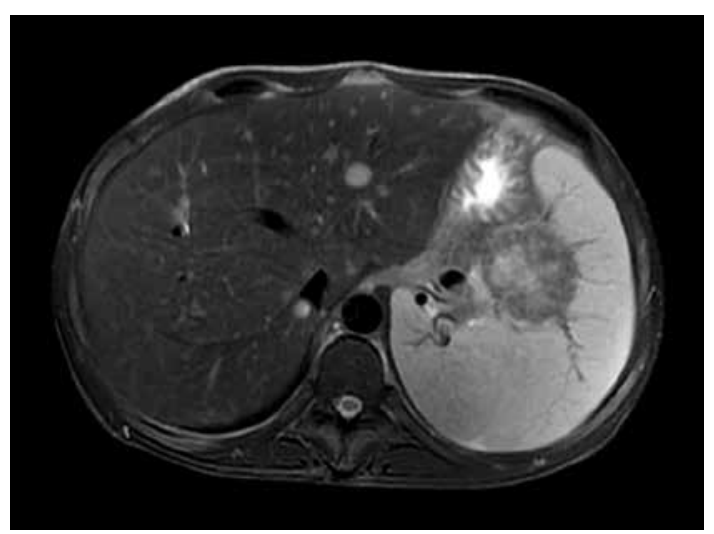

Figure 6. Multiple nodules in liver (T2)

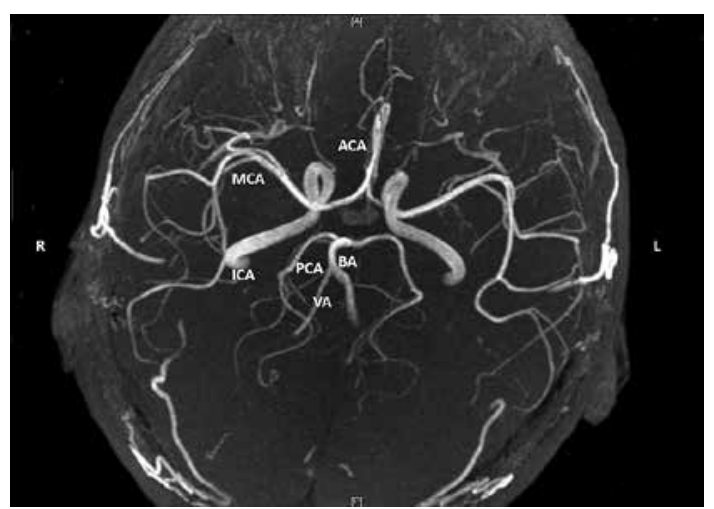

Figure 8. The head of magnetic resonance angiography (MRA) was normal 
deep venous thrombosis of the lower limbs. Three weeks later, the patient received another cranial $\mathrm{CT}$ and the left basal ganglia hemorrhage was almost absorbed. Neurologic examination revealed improved dysarthria and right extremity strength with $1 / 5$ power in the right upper extremity and $2 / 5$ power in the right lower extremity.

The TSC is a multiorgan genetic disease caused by mutations in the TSC1 or TSC2 gene. The classic triad of tuberous sclerosis complex is epilepsy, mental retardation and adenoma sebaceum [1]. Since this triad may not be evident on clinical observation, radiologic examinations play an important role in the diagnosis of TSC. Characteristic signs of TSC vary widely in severity and can include hypopigmented "ash-leaf spots", fibrous plaques on the forehead, angiofibromas on the face (adenoma sebaceum), a shagreen patch on the lower back and fibromas of the nails [1]. This patient came to our urology department 6 months ago before the hemorrhage and was found to have bilaterally enlarged kidneys with diffuse renal disease. In our case, facial angiofibromas and enlarged kidneys with diffuse renal lesions might have led to the possible diagnosis of TSC. However, the right diagnosis was not made until we conducted the cranial CT scan, which revealed the multiple subependymal calcifications. The major features of this case include facial angiofibroma, hypomelanotic macule, ungual fibromas, subependymal nodule, and renal and liver angiomyolipomas. The diagnosis was established based on the combination of physical and radiologic findings [4-6].

The TSC results from inactivating mutations in either TSC1, which is located on chromosome 9q34, or TSC2, which is located on chromosome $16 p 13.3$ [7]. The TSC1-encoded protein hamartin and TSC2-encoded protein tuberin bind to each other to form a functional heterodimer (TSC2: TSC1). TSC1 and TSC2 mutations are equally represented in familial TSC, while mutations in the TSC2 gene are more common in sporadic cases. For some reasons (privacy and disease incurability), our patient refused to have the genetic test.

There has been no report on basal ganglia hemorrhage in patients with TSC. Reports on vascular lesions and hemorrhage in patients with TSC are rare. Hamamoto et al. [8] reported a case of a 19-year-old patient with features of TSC who developed a massive hemorrhage in subependymal giant-cell astrocytoma, causing sudden death. Barbosa-Coutinho et al. [9] reported a case of a 13-year-old boy with TSC manifesting with the classic triad syndrome who died from a massive intratumoral hemorrhage. Both of the 2 patients were found to have a massive parenchymatous brain hemorrhage with intraventricular component in the post mortem examination of the brains. In the hemorrhage, near the lateral ventricle wall, a subependymal giant cell astrocytoma was found. Intracranial aneurysms are extremely rare. Only 16 TSC patients with intracranial aneurysms have been reported. Shyamsunder et al. [10] reported a patient with TSC who had cavernous sinus hemorrhage originating from aneurysms of the posterior communicating artery. Most of the aneurysms were incidental findings on brain imaging performed for other reasons.

Cerebral hemorrhage in the basal ganglia is often caused by rupture of the hypertension-related degenerative vessels. Our patient was found to be hypertensive 6 months before the hemorrhage, but he refused to take antihypertensive medication or monitor blood pressure regularly. Magnetic resonance angiography (MRA) was normal in the neurology ward. Our explanation of the cerebral hemorrhage is chronic hypertension. Most bleeding in hypertension-related intracerebral hemorrhage is at or near the bifurcation of small penetrating arteries. Diffuse renal lesions with chronic renal failure may be the cause of secondary hypertension. The possible cause of the hypertension was diffuse renal disease caused by TSC. Association of TSC with chronic renal failure and hypertension had been described in the literature, although rarely. Momtaz [11] reported a boy with TSC who presented with hypertension and $a b-$ dominal pain associated with bilateral renal cystic disease. According to the Mayo Clinic series [12], after neurological involvement, renal impairment (renal failure or tumoral complications, retroperitoneal hemorrhage, and metastases of renal cell carcinoma) is the second most common cause of death in patients with TSC.

We must admit that our diagnosis was made clinically without genetic testing, which was a major flaw of our work. If we encounter a similar case in the future, we should try to have a multidisciplinary consultation and carry out genetic testing.

In conclusion, important points of our case: (1) there were no aneurysms and hemorrhage was in the basal ganglia; (2) the patient presented with hypertension, possibly caused by diffuse renal lesions; (3) there was no history of seizure. If the patient had received a thorough evaluation and timely blood pressure control treatment during the first outpatient encounter, the intracerebral hemorrhage might have been avoided. Timely follow-up and appropriate intervention could have prevented the catastrophic events of TSC.

\section{Conflict of interest}

The authors declare no conflict of interest. 


\section{References}

1. Hurst JS, Wilcoski S. Recognizing an index case of tuberous sclerosis. Am Fam Physician 2000; 61: 703-8, 710.

2. Baron Y, Barkovich AJ. MR imaging of tuberous sclerosis in neonates and young infants. AJNR Am J Neuroradiol 1999; 20: 907-16.

3. Narayanan V. Tuberous sclerosis complex: genetics to pathogenesis. Pediatr Neurol 2003; 29: 404-9.

4. Northrup H, Krueger DA; International Tuberous Sclerosis Complex Consensus Group. Tuberous sclerosis complex diagnostic criteria update: recommendations of the 2012 international tuberous sclerosis complex consensus conference. Pediatr Neurol 2013; 49: 243-54

5. Roach ES, Gomez MR, Northrup H. Tuberous sclerosis complex consensus conference: revised clinical diagnostic criteria. J Child Neurol 1998; 13: 624-8.

6. Hyman $\mathrm{MH}$, Whittemore $\mathrm{VH}$. National Institutes of Health consensus conference: tuberous sclerosis complex. Arch Neurol 2000; 57: 662-5.

7. Ksenia AO, Peter BC. The tuberous sclerosis complex. Ann N Y Acad Sci 2010; 1184: 87-105.

8. Hamamoto O, Honorato DC, Brito HL, et al. Intratumor hemorrhage in tuberous sclerosis. A case report. Arq Neuropsiquiatr 1994; 52: 435-8.

9. Barbosa-Coutinho LM, Lima EL, Gadret RO, et al. Massive intratumor hemorrhage in tuberous sclerosis. Autopsy study of a case. Arq Neuropsiquiatr 1991; 49: 465-70.

10. Shyamsunder BS, Joel C, Joseph S, et al. Tuberous sclerosis with multiple intracranial aneurysms: atypical tuberous sclerosis diagnosed in adult due to third nerve palsy. Acta Neurol Belg 2010; 110: 89-92.

11. Momtaz HE. Tuberous sclerosis with hypertension and abdominal pain in a child. Iran J Kidney Dis 2010; 4 253-5.

12. Wiederholt WC, Gomez MR, Kurland LT. Incidence and prevalence of tuberous sclerosis in Rochester, Minnesota, 1950 through 1982. Neurology 1985; 35: 600-3. 